\title{
Fundamento, jerarquía y límites del cumplimiento específico. ¿Una tensión entre dos modelos?
}

\author{
Claudia Babamondes Oyarzún* \\ Carlos Pizarro Wilson**
}

\begin{abstract}
RESUMEN
El cumplimiento específico se presenta en forma diversa en el common law y en el derecho continental. En este trabajo se presentan las tensiones que se originan en la diversa comprensión de este remedio. Para esto se expone el lugar que ocupa el cumplimiento específico en el common law y su operatoria ante el incumplimiento, contrastándolo con el derecho continental, tradicionalmente enfocado en privilegiar la palabra dada. Esto permite analizar la recepción del límite al cumplimiento específico por resultar desmedido en relación con su costo y el propósito del contrato, lo que puede justificarse por medio de la buena fe y el abuso del derecho, desechando el deber de mitigar las pérdidas como un mecanismo de control general a los remedios contractuales.
\end{abstract}

Cumplimiento específico - límites a la autonomía de la voluntad - buena fe - abuso del derecho

\section{Basis, hierarchy and limits of specific performance. \\ A strain between two models?}

\begin{abstract}
Specific performance is regulated in common and civil law by two different approaches. This paper shows the stresses originating from the different understanding of this remedy versus the breach of contract. To reach this, it's useful to identify the role of specific performance in the
\end{abstract}

* Licenciada en Ciencias Jurídicas y Sociales, Universidad Diego Portales. Doctora en Derecho, Pontificia Universidad Católica de Valaparaíso. Profesora de derecho civil, Universidad Diego Portales. Correo electrónico: claudia.bahamondes@udp.cl

** Licenciado en Ciencias Jurídicas y Sociales, Universidad de Chile. Doctor en Derecho, Universidad de París II (Pantheón Assas). Profesor de derecho civil, Universidad Diego Portales y Universidad de Chile. Correo electrónico: carlos.pizarro@udp.cl

Este artículo forma parte del proyecto Fondecyt $\mathrm{N}^{\circ} 1150511$.

Artículo recibido el 28 de octubre de 2016 y aceptado para su publicación en este número el 23 de julio de 2018. 
common law system and how it works in case of breach of contract. It also required a comparation with civil law.

This allows to analyze the less application of specific performance related to its cost and the purpose of the contract, this can be justified by good faith and abuse of right, discarding the duty to mitigate as a general instrument of control of the contractual remedies.

Specific performance - freedom of will limits - good faith - extra limitations

\section{INTRODUCCIÓN}

$\mathrm{E}$ n una óptica contemporánea, frente al incumplimiento contractual el acreedor está facultado para ejercer diversas acciones o remedios orientados a satisfacer su interés. Así, es posible que reclame el cumplimiento tal como fue pactado u opte por la resolución del contrato; aun en ambos casos, o de manera autónoma, puede exigir la indemnización de perjuicios. Es lo que en forma tradicional se ha desprendido de la denominada condición resolutoria tácita que contempla el artículo 1489 del Código Civil. Y aunque no se hayan generalizado, siempre están presentes la excepción de contrato no cumplido para los contratos bilaterales y la rebaja del precio en la compraventa ${ }^{1}$. Este ambiente contractual que se genera luego del incumplimiento en los sistemas continentales convoca el juego de múltiples instituciones jurídicas y de remedios.

El derecho del acreedor a exigir el cumplimiento específico del contrato recibe un tratamiento diferente en el common law ${ }^{2}$, presentándose de una manera inversa de

${ }^{1}$ Vidal Olivares, Á., "La pretensión de cumplimiento específico y su inserción en el sistema de remedios por incumplimiento en el Código Civil”, en Corral Talciani, H., Rodríguez Pinto, M. S. (coords.), Estudios de Derecho Civil II: Código Civil y principios generales, nuevos problemas, nuevas soluciones, $2^{\mathrm{a}}$ ed., LexisNexis, Santiago, 2007, pp. 517-538; Vidal Olivares, Á., "El incumplimiento de obligaciones con objeto fungible y los remedios del acreedor afectado: una relectura de las disposiciones del 'Código Civil' sobre incumplimiento”, en Guzmán Brito, A. (ed. científico), El Código Civil de Chile (1855-2005), LexisNexis, Santiago, 2007, pp. 20 y ss; Vidal Olivares, Á., "El incumplimiento y los remedios del acreedor en la Propuesta de modernización del derecho de las obligaciones español", en Revista Chilena de Derecho Privado, $\mathrm{N}^{\circ} 16$, 2011 , pp. 246 y 247; Pizarro Wilson, C., "Hacia un sistema de remedios al incumplimiento contractual", en Guzmán Brito, A. (ed.), Estudios de Derecho Civil III, LegalPublishing, Santiago, 2008, pp. $395-402$.

${ }^{2}$ Acerca del tratamiento de la specific performance en el derecho anglosajón en perspectiva comparada, si bien la literatura es inmensa, destacan Kronman, A. T., "Specific performance", en The University of Chicago Law Review, Vol. XLV, N², Chicago, 1978, pp. 354-365; Treitel, G., Remedies for Breach of Contract: a comparative account, Clarendon Press Oxford, New York, 1989, p. 63 y ss.; Cartwright, J., Contract Law. An introduction to the English Law of Contract for the Civil Lawyer, Hart Publishing, Oxford, 2007, pp. 248251; MackaAy, E., "The civil law of contract", en De Geest, G. (edit.), Contract Law and Economics, VI, Edward Elgar Publishing, Cheltenham, 2011, pp. 448-450; Beale, H., Fauvarque-Cosson, B., Rutgers, J., Tallon, D., Vogenauer, S., Cases, Materials and Text on Contract Law, 2 ed., Hart Publishing, Oxford, 2010, pp. 834-836; Adame-Martínez, M. A., Specific Performance as the Preferred Remedy in Comparative Law and CISG, Thomson Reuters-Aranzadi, Cizur Menor-Navarra, 2013, pp. 34-37; SEverin Fuster, G., "Sobre el carácter secundario y discrecional del remedio del cumplimiento específico en el common law. Perspectiva histórica y aproximación actual”, en Revista Chilena de Derecho, Vol. XLIII, No 1, Santiago, 2016, pp. 7-37. 
aquella que usualmente se asume en el derecho continental. De este modo, la diferencia del ambiente contractual delimita la forma en que operan las distintas acciones por incumplimiento en un determinado sistema. De ahí la importancia de considerar esta perspectiva para el análisis comparado, en tanto instrumento útil para cuestionar nuestro derecho. En la definición de este ambiente también se incorpora un cierto aspecto cultural que refiere a la forma en que se valora el cumplimiento de la palabra dada, ya sea mediante la prestación misma o su traducción en una mera indemnización. Esta diversa mirada incluso influye en la función judicial, la que amplía o restringe las prerrogativas del juez para alterar la voluntad del acreedor, modificando el remedio escogido. En el caso del cumplimiento específico la discrecionalidad para intervenir se reduce y, por lo mismo, puede concebirse como un derecho que admite solo límites legales precisos.

Por cuanto el derecho del acreedor a exigir el cumplimiento específico del contrato recibe un tratamiento diferente en el common law, es que parece interesante interrogarse acerca del mismo y corroborar que en él se reflejan las distintas aproximaciones culturales respecto del fenómeno contractual. Efectivamente, de acuerdo con la comprensión que se tenga del principio de la fuerza obligatoria del contrato es que ha redundado, en torno a este remedio, su supuesta superioridad jerárquica en algunos ordenamientos continentales (I). No obstante, también es posible plantearse el establecimiento de ciertos límites que vendrían a matizar su impronta; límites que se han estudiado de diversas maneras, pero que finalmente se enmarcan en la buena fe contractual (II). Estos interrogantes acerca del fundamento, jerarquía y límites nos prodigarán una cierta panorámica comparada respecto de problemas que circundan el cumplimiento específico de los contratos, lo que permitirá abrir un debate necesario acerca de su comprensión en el derecho local.

\section{El DECAIMIENTO DE LA JERARQUía DEL CUMPLIMIENTO ESPECÍFICO}

Actualmente asistimos a un proceso de globalización o, si se quiere, de mundialización del derecho, que influye no solo en un acercamiento en lo económico, sino que también en la filosofía política de las dos principales tradiciones jurídicas del mundo occidental $^{3}$. No obstante, un ámbito en que aún se plantean divergencias relevantes es a propósito de la ejecución forzada en naturaleza o, como se le ha denominado para realzar su perspectiva sustantiva, el cumplimiento específico de las obligaciones ${ }^{4}$.

\footnotetext{
${ }^{3}$ Grimaldi, M., "El derecho continental frente a la mundialización”, en Pizarro Wilson, C. (coord.), Derecho y economía, Fundación Fernando Fueyo Laneri, Santiago, 2012, pp. 11-14; Zimmermann, R., Derecho romano, derecho contemporáneo, derecho europeo. La tradición del derecho civil en la actualidad, Rodríguez, J. (trad.) Universidad Externado, Bogotá, 2010, p. 138.

${ }^{4}$ Zweigert, K., KöTz, H., Introduction to Comparative Law, 3 ed., Clarendon Press, Oxford, 1998, pp. 180-182; Verdera Server, R., El cumplimiento forzoso de las obligaciones, Publicaciones del Real Colegio de España, Bolonia, 1995, pp. 21-34; Pizarro Wilson, C., "Notas acerca de los límites a la pretensión de cumplimiento específico", en Revista de Derecho de la Universidad Católica del Norte, Vol. XXI, N 1,2014 , pp. 205, 206.
} 
La obligación emanada de un contrato se caracteriza por otorgar al acreedor la posibilidad de compeler al deudor al cumplimiento, recurriendo a la fuerza socialmente organizada ${ }^{5}$. Siguiendo la distinción clásica entre debitum y obligatio, esta permite al acreedor hacer valer lo pactado en los mismos términos en que se haya acordado. Así, el cumplimiento voluntario satisface al acreedor mediante el pago de la obligación. Esto ocurre así en los diversos ordenamientos jurídicos, no detectándose diferencias en torno a la extinción de la obligación por medio del pago o solución de la deuda ${ }^{6}$.

Otro escenario se produce cuando existe un incumplimiento y una conducta refractaria del deudor a satisfacer su deuda, lo que origina los conflictos que se someten a la decisión judicial. En estos casos se recurre al denominado principio de la fuerza obligatoria del contrato, el que aparece bien implantado en los sistemas continentales, como lo muestra el artículo 1545 del Código Civil chileno, el actual artículo 1193 del Code Civil francés ${ }^{7}$ y el artículo 1.091 del Código Civil español. En cada uno de ellos se destaca que el contrato es una ley o tiene su fuerza respecto de las partes, evocando que, una vez celebrado, este se independiza de la voluntad unilateral, pudiendo quedar sin efecto solo por causas legales o por acuerdo mutuo ${ }^{8}$.

Acerca de este principio ha corrido mucha tinta, pues justifica y modela la responsabilidad contractual ${ }^{9}$. Verificado el incumplimiento, al producirse una fractura a la palabra dada, el acreedor puede exigir lo que fue acordado al celebrar ese acto, basado

${ }^{5}$ Este carácter forzado de la ejecución de las obligaciones representa una medida de coacción del derecho frente a la transgresión del contrato. Dicha coacción se monopoliza por la comunidad jurídica y el ordenamiento, que regulan el empleo de la fuerza en las relaciones sociales, estableciendo las condiciones bajo las cuales podrá ejercerse en forma legítima. Kelsen, H., Teoría pura del derecho, Tejerina, J. (Trad.), Editora Nacional, Ciudad de México, 1981, pp. 48-53.

${ }^{6}$ Fueyo Laneri, F., Cumplimiento e incumplimiento de las obligaciones, $3^{\mathrm{a}}$ ed., Editorial Jurídica, Santiago, 2004, pp. 49-59; Alessandri, A., Somarriva, M., Vodanovic, A., Tratado de las obligaciones, tomo III, Editorial Jurídica, Santiago, 2004, pp. 251 y 252; Abeliuk Manasevich, R., Las obligaciones, tomo II, $5^{a}$ ed., Editorial Jurídica, Santiago, 2010, pp. 622, 623, 793; Ramos PAzos, R., De las obligaciones, $3^{\text {a ed., }}$ Editorial Jurídica, Santiago, 2008, p. 244. Es factible destacar que fue durante la época del ius commune en Europa, que el "pago", como modo normal de extinción de las obligaciones, se asimiló al "cumplimiento", en tanto ambos indican la realización de la prestación debida. De este modo, se introduce en la terminología jurídica la sustancial equiparación entre pagamento y solutio, entendida como una liberación jurídica y no ya personal, como ocurría en el Derecho Romano. Diurni, G., "Pagamento (Diritto Intermedio)", en Enciclopedia del Diritto, Giuffrè, Milán, 1981, pp. 541-548.

${ }^{7}$ Correspondiente al antiguo artículo 1134, modificado por la Ordonnance du Président de la République $\mathrm{N}^{\circ}$ 2016-131 du 10 février de 2016.

${ }^{8}$ Un análisis desde la teoría legal acerca de las razones de la obligatoriedad del contrato, pero sin dejar de lado el derecho civil, en Pereira Fredes, E., ¿Por qué obligan los contratos? Justificación normativa de la obligatoriedad del vínculo contractual, Thomson Reuters, Santiago, 2016, p. 9 y ss.

${ }^{9}$ En Chile, de obligatoria consulta es el análisis del principio en López SANTA MARía, J., Los contratos,

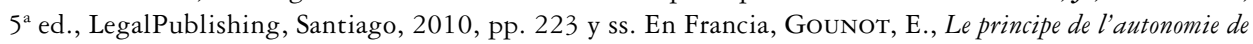
la volonté en droit privé ; contribution à l'étude critique de l'individualisme, thèse, Dijon, 1912; RIEG, A., Le rôle de la volonté dans l'acte juridique en droit civil français et allemand, thèse, LGDJ, Paris, 1961; RouHETTE, G., Contribution à l'étude critique de la notion de contrat, thèse, dactyl., Paris, 1965; ANCEL, P., "Force obligatoire et contenu obligationnel du contrat", en RTD civ., 1999, p. 777; RanOuIL, Veronique, L'autonomie de la volonté: naissance et évolution d'un concept, Presses Universitaires de France, Paris, 1980, p. 21; ChÉNEDÉ, F., 
en el pacta sunt servanda. Salvo los límites usuales que han estado circunscritos a situaciones de imposibilidad, nada impediría someter al deudor a cumplir su palabra. De ahí que tradicionalmente se vincule a la autonomía de la voluntad, como manifestación de la libertad del hombre para obligarse, con la fuerza obligatoria del contrato y con su cumplimiento específico ${ }^{10}$. Si bien la historia muestra la falsedad de la pretendida relación entre la fuerza obligatoria y la autonomía de la voluntad ${ }^{11}$, esta idea se ha instalado con fuerza en el derecho continental y con gran énfasis en los países de la región latinoamericana ${ }^{12}$. La idea es sencilla de explicar. Si hubo incumplimiento, se defrauda la palabra libremente dada, lo que permite al acreedor exigir que ella se ejecute. Y esta vía de cumplimiento es la que debe privilegiarse, pues es la única que concreta efectivamente lo que fue consentido por los contratantes al momento de vincularse. De esta manera, la ejecución específica no solo daría respeto pleno a la fuerza obligatoria del contrato, sino que también haría prevalecer la autonomía y la voluntad libre que las partes depositaron en él ${ }^{13}$; por ello, quienes estudian el derecho comparado no han dudado en recalcar esta característica ${ }^{14}$.

"De l'autonomie de la volonté à la justice commutative. Du mythe à la réalité", en Annuaire de l'institut Michel Villey, No 4, Paris, 2012, p. 156.

${ }^{10}$ Bahamondes Oyarzún, C., "Concurrencia de la indemnización de daños y la pretensión de cumplimiento específico frente al incumplimiento contractual”, en Cuadernos de Análisis Jurídico VII. Incumplimiento contractual. Nuevas perspectivas, Ediciones Universidad Diego Portales, Santiago, 2011, pp. 236, 237,242 y 243.

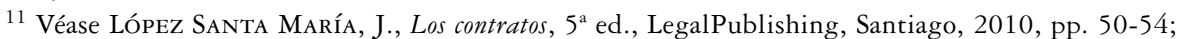
Laithier, Y. M., Étude comparative des sanctions de l'inexécution du contrat, LGDJ, Paris, 2004, pp. 54-58; Pizarro Wilson, C., "Notas críticas sobre el fundamento de la fuerza obligatoria del contrato. Fuentes e interpretación del artículo 1545 del Código Civil chileno”, en Pizarro Wilson, C., Vidal Olivares, Á., Incumplimiento contractual, resolución e indemnización de daños, Editorial de la Universidad del Rosario, Bogotá, 2010, pp. 15-32.

${ }^{12}$ En este sentido, pueden consultarse los informes de Argentina, Brasil, Colombia, Chile, Paraguay, Uruguay y Venezuela, en Pizarro Wilson, C. (coord.), El derecho de los contratos en Latinoamérica (Bases para unos principios de Derecho de los contratos), Fundación Fernando Fueyo Laneri, Santiago, 2012, pp. 20-22, 120-123, 211-214, 297-299, 382-386, 489, 490, 563-565.

${ }^{13}$ Gatica Pacheco, S., Aspectos de la indemnización de perjuicios por incumplimiento del contrato, Editorial Jurídica, Santiago, 1959, pp. 61-63; Ramos Pazos, R., De las obligaciones, $3^{\text {a }}$ ed., Editorial Jurídica, Santiago, 2008, pp. 239-242; Alessandri, A., Somarriva, M., Vodanovic, A., Tratado de las obligaciones, tomo II, Editorial Jurídica, Santiago, 2004, pp. 258-260; Claro Solar, L., Explicaciones de derecho civil chileno y comparado, Vol. 5, Tomo X, Editorial Jurídica, Santiago, 1979, pp. 723-724; Larroumet, Ch., Droit civil. Les obligations, le contrat, Tome III, 5 ed., Economica, Paris, 2003, pp. 96 et 97. La concatenación de estos argumentos, es descrita con agudeza y crítica por LAITHIER, Y. M., Étude comparative des sanctions de l'inexécution du contrat, LGDJ, Paris, 2004, pp. 56, 58-61. Del mismo autor, retomando las ideas expuestas en su tesis, Laithier, Y. M., "La prétendue primauté de l'exécution forcée en nature", en Revue de Droit des Contrats, 2006, p. 161 y ss.

14 "Conocemos la opinión comúnmente aceptada según la cual, en derecho francés, la regla es la ejecución forzada en naturaleza, la excepción la ejecución por equivalencia”. BELlivier, F. y SEFTON-GREEN, R., "Force obligatoire et exécution en nature du contrat en droit français et anglais. Bonnes et mauvaises surprises du comparatisme”, en Études offertes à Jacques Ghestin. Le contrat au debut du XXI siècle, LGDJ, Paris, 2001, p. 91 y ss. Otro ejercicio de derecho comparado en Fauvarque-Cosson, B. "Regards comparatiste sur l'exécution forcée en nature”, en Revue de Droit des Contrats, 2006-2, pp. 529-542. 
Según veremos, el actual derecho francés infligió un duro golpe a esta primacía absoluta del cumplimiento específico mediante el establecimiento de un límite económico, entendiendo que este remedio no procede si existe una desproporción manifiesta entre el costo para el deudor y el interés para el acreedor ${ }^{15}$. Este cambio no es menor. Aquella primacía fue fruto de un lento desarrollo histórico asentado en la jurisprudencia, aun cuando ello implicara alejarse de las reglas positivas plasmadas en el antiguo Código Civil francés, en particular el artículo $1142^{16}$.

La explicación acerca de esta supremacía del cumplimiento contra texto expreso, erigida al alero de la doctrina y la jurisprudencia, ha sido denominada críticamente como la "lucha por la ejecución forzada"17. Y fue la relación entre la fuerza obligatoria y la ejecución forzada lo que justificó por años su posición privilegiada; posición que con la reforma francesa queda debilitada, toda vez que el artículo 1217 no "articula una jerarquía"18, sino una simple enumeración que no ha estado exenta de críticas ${ }^{19}$.

Con todo, y a pesar de esta uniformidad entre las distintas sanciones por inejecución, se ha fortalecido el cumplimiento en el ámbito de los contratos preparatorios, a lo que cabría agregar un cierto reconocimiento en la extensión de su ámbito de aplicación por la jurisprudencia de la Corte de Casación francesa. El nuevo artículo 1221 del Code faculta al acreedor a demandar el cumplimiento específico sin importar la naturaleza de la obligación -en su antigua clasificación de dar, hacer o no hacer-y reconoce en su favor un derecho para que pueda escoger este remedio, el que no se le impone ni por el deudor ni tampoco por el juez ${ }^{20}$. Por otra parte, si se incumple una promesa unilateral, en que el tercero que haya contratado en infracción de esta la haya conocido, el acto podrá ser anulado, retrotrayendo sus efectos al estado anterior de la violación, lo que permite el cumplimiento exacto del contrato preparatorio y, en consecuencia, del definitivo ${ }^{21}$.

Por tanto, la reforma francesa permite evitar los posibles excesos de la primacía de la ejecución forzada por la vía del límite económico y es, en este sentido, que el nuevo Código debilita este remedio en su comprensión tradicional.

${ }^{15}$ Véase nuevo artículo 1221 del Code Civil.

${ }^{16}$ En este sentido se sostuvo "cada uno sabe, en efecto, que, en desmedro del inmovilismo de la ley, el derecho de la ejecución forzada sensiblemente ha evolucionado y nadie controvierte hoy que la ejecución forzada de las obligaciones de hacer o de no hacer constituye el principio y su ejecución, por equivalencia, la excepción”. Mazeaud, D. Comentario de jurisprudencia, nota en Dalloz, 1997, Corte de casación, 30 de abril de 1997, p. 476

${ }^{17}$ LaIthier, Y. M., Étude comparative des sanctions de l'inexécution du contrat, LGDJ, Paris, 2004, pp. 38 y ss.

18 Delebecque, Ph. "L'articulation et l'aménagement des sanctions de l'inexécution du contrat", en Droit et Patrimoine, 2016, p. 63.

19 Deshayes, O., Genicon, T., Laithier, Y. M., Réforme du droit des contrats, du régime général et de la preuve des obligations. Commentaire article par article, Paris, LexisNexis, 2016, 475.

${ }^{20}$ Deshayes, O., Genicon, T., Laithier, Y. M., Réforme du droit des contrats, du régime général et de la preuve des obligations. Commentaire article par article, Paris, LexisNexis, 2016, p. 485 y ss.

${ }^{21}$ Véase nuevo artículo 1124 inciso final del Code civil. Otro tanto puede constatarse en el terreno del pacto de preferencia, cuyo incumplimiento habilita al beneficiario a reclamar la nulidad o sustituirse en el contrato que se celebró en violación del pacto y, además, reclamar la indemnización de perjuicios. Véase el artículo 1123 inciso $2^{\circ}$ del Code civil. 
Por consiguiente, los sistemas continentales, particularmente el francés -al menos hasta antes de la reforma implementada- y con persistencia los modelos legales latinos, han erigido el cumplimiento en naturaleza sobre un pedestal, lo que los ha llevado a elevar la jerarquía de este remedio contractual, posicionando su absoluta primacía frente a los demás medios de tutela ${ }^{22}$. De ahí que, para estos sistemas, la palabra dada haya significado históricamente marginar instituciones como la imprevisión o la minimización del daño a los libros de derecho comparado ${ }^{23}$. Este ha sido, también, un argumento para descartar la revisión del contrato en Chile, abogando por mantener la obligatoriedad con carácter firme, sin atenuaciones.

En el derecho continental la cercanía con el cumplimiento específico es fácilmente constatable. Díez-Picazo expresa que "la primera medida de reacción que en el orden lógico ocurre es la acción dirigida a obtener el comportamiento omitido y a obtenerlo en forma específica, del mismo modo que debió ser y no fue realizado por el deudor, lo que, naturalmente, es un derecho del acreedor, llamado 'pretensión de cumplimiento' a la acción o facultad que se confiere al acreedor para obtener esa finalidad" 24 . Lo mismo se ha planteado a nivel local acerca de esta figura ${ }^{25}$.

Sin embargo, esta no es la única mirada respecto de la fuerza obligatoria ni, por cierto, respecto del cumplimiento. El vínculo intrínseco y casi absoluto que los sistemas continentales establecen entre la fuerza obligatoria y el fundamento y mecanismo que modela la ejecución del contrato, no se encuentra presente en la tradición del common law. Lo que no significa que los contratos no gocen de dicha obligatoriedad, sino solo que la forma de entenderla es diferente. La enforceability expone al deudor incumplidor

${ }^{22}$ Pizarro Wilson, C., "Los remedios al incumplimiento contractual en los proyectos franceses de reforma del Derecho de contratos", en Revista de Derecho de la Pontificia Universidad Católica de Valparaíso, Vol. XXXVI, Nº 1, 2011, pp. 126-130; Vidal Olivares, Á., "La pretensión de cumplimiento específico y su inserción en el sistema de remedios por incumplimiento en el Código Civil”, en Corral TALCiani, H., Rodríguez Pinto, M. S. (coords.), Estudios de Derecho Civil II: Código Civil y principios generales, nuevos problemas, nuevas soluciones, $2^{\mathrm{a}}$ ed., LexisNexis, Santiago, 2007, pp. 517 y ss.; VIDAl Olivares, Á., "El incumplimiento de obligaciones con objeto fungible y los remedios del acreedor afectado: una relectura de las disposiciones del 'Código Civil' sobre incumplimiento”, en Guzmán Brito, A. (ed. científico), El Código Civil de Chile (1855-2005), LexisNexis, Santiago, 2007, pp. 507-511; BAHAmondes Oyarzún, C., "Concurrencia de la indemnización de daños y la pretensión de cumplimiento específico frente al incumplimiento contractual”, en Cuadernos de Análisis Jurídico VII. Incumplimiento contractual. Nuevas perspectivas, Ediciones Universidad Diego Portales, Santiago, 2011, pp. 241-243; PeÑAllillo Arévalo, D., Las obligaciones: teoría general y clasificaciones. La resolución por incumplimiento, Editorial Jurídica, Santiago, 2003, p. 40.

${ }^{23}$ Sin embargo, es relevante anotar que el cambio en la legislación relativa al derecho de los contratos en Francia morigeró en gran medida esta visión estricta, porque se introduce la imprevisión. Así lo dispone la Ordonnance No 2016-131 du 10 février de 2016, en el art. 1195.

${ }^{24}$ DíEz-PiCAzo, L., Fundamentos del derecho civil patrimonial. II. Las relaciones obligatorias, 6 a ed., Thomson Reuters-Civitas, Cizur Menor-Navarra, 2008, p. 775.

25 Pizarro Wilson, C., "Notas acerca de los límites a la pretensión de cumplimiento específico", en Revista de Derecho de la Universidad Católica del Norte, Vol. XXI, N 1, 2014, pp. 206 y 207. Y en forma más extensa Bahamondes Oyarzún, C., "Concurrencia de la indemnización de daños y la pretensión de cumplimiento específico frente al incumplimiento contractual”, en Cuadernos de Análisis Jurídico VII. Incumplimiento contractual. Nuevas perspectivas, Ediciones Universidad Diego Portales, Santiago, 2011, pp. 237 y ss. 
al ejercicio de un remedio por parte del acreedor, pero este no forzará la verificación de la prestación misma, sino que terminará la relación contractual; y este término, por regla general, se efectúa mediante la entrega de una indemnización ${ }^{26}$.

Es evidente entonces que para la doctrina del breach of contract el remedio que corresponde aplicar es la indemnización, que deberá pagarse por los daños que provoca la infracción al contrato, relegando al cumplimiento in natura a casos aislados de equity ${ }^{27}$. En estas hipótesis, el juez puede dar lugar a la specific performance o a la injuction -si se trata de obligaciones de abstención- cuando advierta que la indemnización no logrará satisfacer, de manera adecuada, el interés del acreedor ${ }^{28}$. Y son estos espacios los que serán cubiertos por el adecuacy test, que identifica ciertos criterios jurisprudenciales que permiten la procedencia de la specific performance ${ }^{29}$. Dichos criterios refieren a casos en que el equivalente monetario es incapaz de reemplazar o sustituir en forma idónea la prestación prometida; si resulta dificultoso avaluar los daños o si se trata de la venta de una especie o cuerpo cierto. El contenido de estos estándares queda entregado a la discrecionalidad de los jueces, quienes son estrictos al momento de decretar la specific performance, debido a las severas consecuencias que se le asocian en la persona, intimidad y derechos del deudor ${ }^{30}$.

En este sentido, es usual encontrar en el derecho anglosajón afirmaciones que indiquen que Specific performance is a discretionary remedy. The Court has a choice in the matter and, although this does not mean that the choice will be exercised in an arbitrary or capricious manner, the Court can considerer whether it would be fair to grant the remedy and refuse it in circumstances which would not justify a refusal of the common law remedy of damage ${ }^{31}$.

${ }^{26}$ LaITHIER, Y. M., Étude comparative des sanctions de l'inexécution du contrat, LGDJ, Paris, 2004, pp. 33, 34.

27 Treitel, G., Remedies for Breach of Contract: a comparative account, Clarendon Press Oxford, New York, 1989, p. 63; Beatson, J., Burrows, A., Catwright, J., Anson's Law of Contract, 29 ed., Oxford University Press, New York, 2010, p. 573.

${ }^{28}$ Verdera Server, R., El cumplimiento forzoso de las obligaciones, Publicaciones del Real Colegio de España, Bolonia, 1995, pp. 124-133; Ruz LÁRTiGA, G., "El derecho a la ejecución in natura en el cumplimiento de las obligaciones en Chile", en Departamento de Derecho Privado de la Facultad de Ciencias Jurídicas y Sociales de la Universidad de Concepción (ed.), Estudios de Derecho Civil V, LegalPublishing, Santiago, 2010, p. 615; Barros Bourie, E., "Finalidad y alcance de las acciones y los remedios contractuales”, en GuZMÁN Brito, A. (ed. científico), Estudios de derecho civil III, LexisNexis, Santiago, 2008, p. 410; Treitel, G., The law of contract, Sweet \& Maxwell, London, 1999, pp. 949, 950.

${ }^{29}$ Farnsworth, E. A., Contracts, $4^{\mathrm{a}}$ ed., Aspen Publishers, Nueva York, 2004, p. 931; Beatson, J., Anson's Law of Contract, 28 ed., Oxford University Press, New York, 2002, pp. 632-637; Severin Fuster, G., "El cumplimiento específico de los contratos de servicio en el derecho español", en Revista de Derecho Privado de la Universidad Externado de Colombia, No 30, 2016; EISEnberg, M. A., "Actual and Virtual Specific Performance. The Theory of Efficient Breach and the Indifference Principle in Contract Law", en California Law Review, Vol. 93, No 4, California, 2005, pp. 1016-1017.

${ }^{30}$ Bellivier, F. y Sefton-Green, R., "Force obligatoire et exécution en nature du contrat en droit français et anglais. Bonnes et mauvaises surprises du comparatisme”, en Études offertes à Jacques Ghestin. Le contrat au debut du XXI siècle, LGDJ, Paris, 2001, p. 95.

31 Beatson, J., Burrows, A., Catwright, J., Anson's Law of Contract, 29 ed., Oxford University Press, New York, 2010, p. 580. 
En el derecho angloamericano el acreedor solo es compensado por la indemnización, sin que exista una distinción entre cumplimiento por equivalencia, ni resarcimiento, integrando en la expresión damages ambos rubros de daños. Y esta indemnización omnicomprensiva en ningún caso implica poner en jaque o desconocer la fuerza obligatoria del contrato. Por el contrario, este remedio, entregado como una suma global, garantiza que el acreedor quedará siempre indemne ${ }^{32}$. Ello se ve confirmado por el mismo hecho de que, en caso de no constituir una medida que satisfaga el interés dañado, el juez podrá recurrir a la equity para decretar la specific performance o la injuction.

Observamos, entonces, que la diferencia crucial radica en que el cumplimiento específico en los sistemas continentales es un remedio al alcance del acreedor, con independencia de que procedan límites que impidan su práctica una vez que este se configura. Y pese a que los modelos de unificación del derecho de contratos y aquellos esfuerzos de reforma tienden a darle un lugar más equilibrado, en ningún caso ha sido relegado a una excepción. Mientras el cumplimiento específico cae de su pedestal en el sistema continental, al ser objeto de atenuaciones, no llega a ser un remedio marginal, ni la indemnización se ha erigido como aquel por antonomasia.

¿Por qué la diferencia entre estos modelos? ¿Qué explica que en un sistema sea fortalecido el cumplimiento específico y en el otro, una excepción, mientras que la indemnización de perjuicios pasa a ser la regla general? Sin duda hay un asunto cultural detrás, pero también jurídico o filosófico, al comprender los efectos del incumplimiento de diversa manera. Como se señaló, para la tradición del civil law existe un vínculo indisoluble entre el cumplimiento en naturaleza y la fuerza obligatoria del contrato; la solución obvia es que el interés del acreedor se satisfará si aquel se ejecuta de la forma inicialmente pactada, confirmando, así, su fuerza obligatoria ${ }^{33}$. En cambio, para el common law, el interés del acreedor y la obligatoriedad del contrato pueden entenderse conformes con la entrega de la indemnización por daños, aunque aquel se termine. Con ella es posible acudir al mercado y obtener la prestación incumplida por otras vías ${ }^{34}$. Y si la indemnización no parece adecuada, se decretará el cumplimiento mediante la aplicación de la equity.

32 De ahí que en Inglaterra no haya posibilidad de exigir el cumplimiento forzado a propósito de un contrato preparatorio, ni menos que se derive responsabilidad precontractual por ruptura de negociaciones. Véase en este sentido A.G of Hong Kong v. Humpreys Estates (Queens Gardens) Ltd. (1987), AC 114 y Walford v. Miles (1992) 1 All ER 453, H.L., citados por Bellivier, F. y Sefton-Green, R., "Force obligatoire et exécution en nature du contrat en droit français et anglais. Bonnes et mauvaises surprises du comparatisme", en Études offertes à Jacques Ghestin. Le contrat au debut du XXI siècle, LGDJ, Paris, 2001, p. 94; HofmanN, N., "Interpretation Rules and Good Faith as Obstacles to the UK's Ratification of the CISG and Harmonization of Contract Law in Europe”, en Pace International Law Review, 2010, pp. 145-181, disponible en http://www.cisg.law.pace.edu/cisg/biblio/hofmann.html, fecha de consulta 8 de marzo de 2017.

${ }^{33}$ LAITHier, Y. M., Étude comparative des sanctions de l'inexécution du contrat, LGDJ, Paris, 2004, pp. 39 y ss., especialmente p. 58.

34 Ruz LÁrtiga, G., "El derecho a la ejecución in natura en el cumplimiento de las obligaciones en Chile", en Departamento de la Derecho Privado de la Facultad de Ciencias Jurídicas y Sociales de la Universidad de Concepción (ed.), Estudios de Derecho Civil V, LegalPublishing, Santiago, 2010, pp. 615, 616. 
Podemos indicar que la fuerza obligatoria y su relación con la autonomía de la voluntad han marcado un modelo de responsabilidad contractual en el derecho continental, que dista de aquel del common law. Mientras la palabra dada en el primero se mira como un valor socialmente relevante e insoslayable, en el segundo lo sustancial es la satisfacción del acreedor, sin importar que esta se concrete mediante otros caminos, en particular, la indemnización. Mientras en el primero reinaría la palabra dada en la doctrina y la jurisprudencia, en el segundo prima el pragmatismo ${ }^{35}$.

Estos ambientes contractuales y la cultura jurídica marcan la diferencia frente a los diversos fenómenos que desencadenan el cumplimiento e incumplimiento del contrato. Los sistemas continentales -el chileno por lo pronto- reaccionan otorgando múltiples remedios al acreedor que, con mayor o menor énfasis, quedan supeditados en su elección a las respectivas condiciones de operación. En cambio, en el modelo anglosajón, el acreedor debe considerar la procedencia de la indemnización, pero además el surgimiento de un deber de minimizar su daño. La entrega del remedio indemnizatorio es la que justifica en gran medida que haya lugar al duty to mitigate, pues, como se explica, los perjuicios deberían acotarse por su propia conducta, evitando cualquier agravamiento y, con ello, una reducción en su importe ${ }^{36}$. Hasta ahora, esta última figura ha sido desconocida en Chile y en la mayoría de los sistemas legales en Latinoamérica, lo que contrasta con una paulatina y persistente acogida en Europa.

Esta progresiva aceptación ha hecho que alguna doctrina continental entienda que la carga de mitigar las pérdidas que recae sobre el acreedor podría operar también como un límite al cumplimiento específico. Eso sí, dicha restricción se aplicaría de manera mediata y con una interpretación extensiva respecto de la gestión misma de los reme$\operatorname{dios}^{37}$. En este sentido, se plantea que la indemnización que acompaña a la acción de

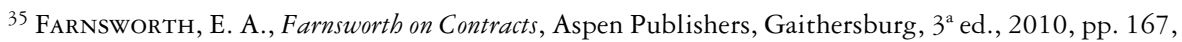
168; Flour, J., Aubert, J.L, Les obligations. Le rapport d'obligation, Sirey, Paris, 1999, tome III, p. 95; Pizarro Wilson, C., "Notas acerca de los límites a la pretensión de cumplimiento específico", en Revista de Derecho de la Universidad Católica del Norte, Vol. XXI, N 1, 2014, p. 208.

${ }^{36}$ Acerca de la carga de mitigar los daños en el caso latinoamericano y su justificación para introducirla, San Martín Neira, L., La carga del perjudicado de evitar o mitigar el daño. Estudio histórico-comparado, Universidad Externado de Colombia, Bogotá, 2012, pp. 245 y ss. Y en particular, pp. 291 y ss.; PIZARro Wilson, C., "Contra el fatalismo del perjuicio. A propósito del deber de mitigar el daño", en Revista de Derecho, Pontificia Universidad Católica de Valparaíso, Vol. XLI, 2013, pp. 69-82; Vidal Olivares, Á., "La carga de mitigar las pérdidas del acreedor", en GuZMán Brito, Alejandro (coordinador), en Estudios de Derecho Civil III, Santiago, 2008, pp. 429 y ss.; Gandarillas Serani, C., "Algunas consideraciones acerca del deber de mitigación o minimización del daño frente al incumplimiento contractual”, en PizArro, C. (coord.), Estudios de Derecho Civil IV, LegalPublihing, Santiago, 2009, pp. 447 ss. En forma más tangencial: Aedo Barrena, C., "Cargas o deberes en la posición contractual del acreedor con especial referencia a su mora de recibir, en Colección de estudios de Derecho civil en homenaje a la profesora Inés Pardo de Carvallo, Ediciones Universitarias de Valparaíso, Valparaíso, 2008, pp. 281 y ss.

37 Vidal Olivares, Á., "La gestión razonable de los efectos del incumplimiento en la compraventa internacional", en Revista de Derecho de la Universidad Austral de Chile, N², Vol. XVIII, 2005, disponible en http://www.scielo.cl/scielo.php?script=sci_arttext\&pid=S0718-09502005000200003, consultada el 24 de octubre de 2017; Vidal Olivares, Á., La protección del comprador. Régimen de la Convención de Viena y su contraste con el Código Civil, Ediciones Universitarias de Valparaíso, Valparaíso, 2006, pp. 163 y ss 
cumplimiento in natura debiera reducirse cuando esta tenga un costo excesivo respecto del interés del acreedor. Será la disminución de la indemnización, sumado al posible rechazo de la demanda, lo que incitará al acreedor a buscar una solución alternativa en el mercado para no seguir agravando sus perjuicios. Con ello, los ordenamientos de raíz continental no solo se aproximarían, en alguna medida, a aquellos angloamericanos, sino que también propenden a instaurar un sistema equilibrado que protege los intereses de las partes contratantes.

Pero ¿es posible hacer extensiva esta institución tan propia de la tradición anglosajona a un remedio eminentemente continental? Este acercamiento entre los dos sistemas ¿es efectivo o constituye uno de los anhelos que surgen con la globalización?

\section{El CUMPLIMIENTO ESPECÍfICO Y SUS LÍMITES ¿UN ACERCAMIENTO ENTRE DOS SISTEMAS?}

Establecida la diferencia tradicional en el tratamiento del remedio de cumplimiento específico en el common law y el derecho continental, hemos podido constatar que la tensión entre ambos modelos se ha ido atenuando, desde el nuevo derecho galo hasta nuestro continente, aunque sin alcanzar uniformidad, considerando que, en su posición y relación con los demás remedios persisten diferencias. El carácter discrecional del cumplimiento específico, propio del common law, resulta distante del reconocimiento de un derecho plasmado que cuenta con una acción para reclamar dicho cumplimiento en el derecho continental.

Sin embargo, hoy es posible aseverar que la doctrina local acepta el avance hacia el reconocimiento de ciertos límites que morigeren su exigencia irrestricta, incluso más allá de aquellos que siempre han sido $\operatorname{considerados}^{38}$. Lo anterior se plantea especialmente en casos en que su imposición material ponga en grave desmedro la situación del deudor -desde un punto de vista económico- y no signifique, para el acreedor, una mejor solución frente a ese incumplimiento contractual ${ }^{39}$. Se pondera el derecho a reclamar en forma exacta lo que se pactó, con los efectos que se siguen desde una perspectiva económica para el deudor, cuyo incumplimiento puede remediarse, poniendo atención en el interés del acreedor.

38 Por cierto, esto se entronca con la idea de horizontalidad de los remedios contractuales por incumplimiento, permitiendo al acreedor escoger aquel que mejor satisfaga su interés, de acuerdo con el propósito práctico del contrato, y siempre que se cumplan las condiciones generales y particulares de los mismos. Morales Moreno, Antonio Manuel, "El 'propósito práctico', y la idea de negocio jurídico en Federico de Castro y Bravo (Notas en torno a la significación de la utilidad de la cosa en los negocios del tráfico)", en Anuario de Derecho Civil, No 4, Vol. XXXVI, Madrid, 1983, pp. 323-348; Morales Moreno, Antonio Manuel, "La noción unitaria de incumplimiento en la Propuesta de Modernización del Código Civil", en González Pacanowska, Isabel, García Pérez, Carmen Leonor (coords.), Estudios sobre incumplimiento y resolución, Thomson Reuters-Aranzadi, Cizur Menor-Navarra, 2015, pp. 23-40.

${ }^{39}$ Severin Fuster, G., "El cumplimiento específico de los contratos de servicio en el derecho español", en Revista de Derecho Privado de la Universidad Externado de Colombia, No 30, 2016, pp. 169-186. 
No se trata de cumplir a todo evento, generando un descalabro económico para el deudor, si es que existe una alternativa idónea que satisfaga -en una medida comparable- el interés del acreedor. El derecho, en caso de incumplimiento, no debe orientarse a satisfacer caprichos, sino que debe considerar la intención que se tuvo en vista al momento de contratar, evitando así el abuso o mala fe del acreedor en la gestión de los remedios contractuales ${ }^{40}$.

En Chile este tema ha sido desarrollado por alguna doctrina, la que ha evidenciado no solo los límites clásicos que restringen la procedencia del cumplimiento específico ${ }^{41}$, sino que ha focalizado también el asunto en la posibilidad de introducir márgenes de índole económica a este remedio ${ }^{42}$. Dichas restricciones podrían ser implementadas, según se sugiere, mediante instituciones eminentemente continentales, esto es, por medio de las tradicionales válvulas en este ámbito: el abuso del derecho ${ }^{43}$ o la buena $\mathrm{fe}^{44}$.

No obstante, esta propuesta no constituye hoy una novedad en el derecho continental. Tanto el proyecto de reforma al derecho de las obligaciones español ${ }^{45}$ como algunos de los que se presentaron en Francia ${ }^{46}$ y la Ordonnance que modificó el Code, prevén este límite al cumplimiento específico ${ }^{47}$.

${ }^{40}$ Vidal Olivares, Álvaro, "La pretensión de cumplimiento específico de las obligaciones no dinerarias y los costes excesivos para el deudor como límite a su ejercicio", en Vidal Olivares, Álvaro, SEvErin Fuster, Gonzalo, Mejías Alonzo, Claudia (eds.), Estudios de derecho civil X, Thomson Reuters-La Ley, Santiago, 2015, pp. 555 y ss.

41 Bahamondes Oyarzún, C., "Concurrencia de la indemnización de daños y la pretensión de cumplimiento específico frente al incumplimiento contractual”, en Cuadernos de Análisis Jurídico VII. Incumplimiento contractual. Nuevas perspectivas, Ediciones Universidad Diego Portales, Santiago, 2011, pp. 256258; Pizarro Wilson, C., "Notas acerca de los límites a la pretensión de cumplimiento específico", en Revista de Derecho de la Universidad Católica del Norte, Vol. XXI, N 1, 2014, pp. 203 y ss.

42 Vidal Olivares, Á., "La pretensión de cumplimiento específico y su inserción en el sistema de remedios por incumplimiento en el Código Civil”, en Corral Talciani, H., Rodríguez Pinto, M. S. (coords.), Estudios de Derecho Civil II: Código Civil y principios generales, nuevos problemas, nuevas soluciones, $2^{\mathrm{a}} \mathrm{ed}$., LexisNexis, Santiago, 2007, p. 527.

${ }^{43}$ López DíAz, P, "El abuso del derecho de opción del acreedor y su importancia en la construcción de un sistema equilibrado de remedios", en Revista Chilena de Derecho Privado, No 19, Santiago, 2012, pp. 13 y siguientes, en particular, pp. 35 y siguientes; PizArro Wilson, C., "Notas acerca de los límites a la pretensión de cumplimiento específico", en Revista de Derecho de la Universidad Católica del Norte, Vol. XXI, $\mathrm{N}^{\circ}$ 1, 2014, pp. 210-213.

${ }^{44}$ Severin Fuster, G., "El cumplimiento específico de los contratos de servicio en el derecho español", en Revista de Derecho Privado de la Universidad Externado de Colombia, No 30, 2016, pp. 179-183.

${ }^{45}$ Vidal Olivares, Á., "El incumplimiento y los remedios del acreedor en la Propuesta de modernización del derecho de las obligaciones español", en Revista Chilena de Derecho Privado, No 16, 2011, pp. 276-280. En particular, artículo 1192 de la Propuesta de Modernización del Código Civil español en materia de Obligaciones y Contratos.

${ }^{46}$ Pizarro Wilson, C., "Los remedios al incumplimiento contractual en los proyectos franceses de reforma del Derecho de contratos", en Revista de Derecho de la Pontificia Universidad Católica de Valparaíso, Vol. XXXVI, N 1, 2011, pp. 126-130; Laithier, Y. M., "Les sanctions de l'inexécutions du contrat", en Revue des contrats, abril, hors serie, 2016, pp. 35 y ss., en particular, p. 42.

${ }^{47}$ Ordonnance du Président de la République N 2016-131 du 10 février de 2016, article 1221: “Art. 1221.- Le créancier d'une obligation peut, après mise en demeure, en poursuivre l'exécution en nature sauf 
El problema puede graficarse de mejor manera gracias al célebre ejemplo que aparece en el Draft Common Frame of Reference ${ }^{48}$. Se trata de la venta de un yate que, durante la travesía para su entrega, se hunde. Y aunque es posible sacarlo del fondo del mar, el costo de esta operación es tan alto, que transforma la prestación del vendedor y la eleva extremadamente en su onerosidad, si esta se cumpliera tal como se acordó ${ }^{49}$.

También se presenta la problemática a propósito de uno de los casos que usualmente cita la doctrina española. En este, se acoge una acción reivindicatoria y se obliga al reivindicado a devolver un inmueble libre de escombros y materiales. Tomando en cuenta que el costo de limpieza era de cincuenta millones de pesetas y de que el terreno estaba avaluado en cien mil pesetas, el Tribunal Constitucional español solo condenó al pago de una indemnización de daños, coincidiendo así con el criterio de los tribunales de instancia ${ }^{50}$.

De esta forma, la pregunta que surge es si, en este tipo de casos, sería preferible que el acreedor satisfaga su interés con una indemnización de perjuicios o si el cumplimiento específico puede siempre otorgarse por el juez, sin restricciones. Esta problemática no debe conducir a pensar solo en una cuestión financiera o en aplicar una respuesta simplemente monetaria al asunto. Esta vez se debe recurrir al ambiente contractual y a las variantes que en este ha introducido el llamado "nuevo derecho de la contratación" 51 .

En efecto, incluso en los sistemas continentales, donde durante largo tiempo primó el cumplimiento específico entre las distintas acciones del acreedor, el nuevo influjo de ideas ha permitido crear más espacios de flexibilidad frente a instituciones tan arraigadas como esta, avanzando, al menos, en el cuestionamiento del ejercicio a todo evento del cumplimiento del contrato.

Considerando que ciertas hipótesis pueden dar lugar a una situación de abuso del derecho $^{52}$ es posible ir más allá y recurrir a fronteras normativas, instaladas -desde siempre, pero sin ser así interpretadas- en los propios códigos civiles de impronta continental. Si las nuevas pautas pertinentes a contratación consideran que el acreedor se encuentra en el centro del problema del incumplimiento, es razonable que sea este

si cette exécution est impossible ou s'il existe une disproportion manifeste entre son cô̂t pour le débiteur et son intérêt pour le créancier" (las cursivas son nuestras).

48 Disponible en http://ec.europa.eu/justice/contract/files/european-private-law_en.pdf, visitada el 23 de septiembre de 2017.

${ }^{49}$ Denis, P., "Book III performance and non-performance of obligations and corresponding rights in the DCFR”, en Sagaert, V., Storme, M. E. y Terryn, E. (eds.), The Draft Common Frame of Reference: national and comparative perspectives, Intersentia Publishing Ltd, Cambridge, Antwerp, Portland, 2012, pp. 40 y 41.

50 Morales Moreno, A. M., La modernización del derecho de obligaciones, Thomson-Civitas Aranzadi, Cizur Menor-Navarra, 2006, p. 68.

${ }^{51}$ Una aproximación en este sentido en Chile en BARros Bourie, E., "La diferencia entre estar obligado y ser responsable en el derecho de los contratos", Corral Talciani, H., Rodríguez Pinto, M. S. (coords.), en Estudios de Derecho Civil II, LexisNexis, Santiago, 2006, p. 748.

${ }^{52}$ López Díaz, P., "El abuso del derecho de opción del acreedor y su importancia en la construcción de un sistema equilibrado de remedios”, en Revista Chilena de Derecho Privado, No 19, Santiago, 2012, p. 41 y ss. 
quien pueda escoger, entre diversos remedios, aquel que mejor satisfaga su interés contractual, bajo el supuesto que se satisfagan sus condiciones objetivas de procedencia. Sin embargo, también se debe considerar que el mismo deba realizar una elección razonable, simplemente basándose en la buena fe. Así, un elemento inherente al derecho de los contratos será la necesaria proporcionalidad en el ejercicio de los derechos reconocidos al acreedor. Esta racionalidad "es un estándar de conducta arreglada a los imperativos éticos exigibles de acuerdo con la conciencia social imperante" 53 .

Si bien una fórmula como esta no aporta mucho para la solución de casos específicos, pues está plagada de términos con textura amplia, resulta útil el intento de concretizar dicho principio y adoptar al menos una directriz que permita la solución de los casos complejos. Siguiendo a Díez-Picazo, una manifestación de este principio a propósito de la interpretación de los contratos supone "una lealtad y una corrección en su misma elaboración, es decir, entendiendo que las partes al redactarlas quisieron expresarse según el modo normal propio de gentes honestas y no buscando circunloquios, confusiones deliberadas u oscuridades" 54 . De modo que, si en su opción el acreedor transgrede ese estándar de conducta, infringirá el art. 1546 y por esta razón, corresponderá negarle el remedio escogido 55 .

Como se puede apreciar, en este caso no se trata de que estén ausentes algunas de las condiciones de operación del remedio, sino que, siendo este aplicable, se establece una restricción a dicha procedencia, configurando, consecuencialmente, un genuino límite a la elección por parte del acreedor. Sin embargo, para que ese límite tenga cabida debe acreditarse que la alternativa -por ejemplo, aquella indemnizatoria-satisface, al menos en forma equiparable, el interés del acreedor. De esta forma, se logra un equilibrio en el régimen de remedios por incumplimiento, por cuanto se respeta el principio de buena fe contractual, al proscribir el ejercicio irrazonable de las acciones y también se procura evitar una severa lesión al propósito práctico previsto en el contrato ${ }^{56}$.

Este límite puede también construirse sobre la base de la teoría del abuso del derecho e implicará el rechazo de la demanda de cumplimiento específico hecha por el acreedor. En este sentido, el juez considerará la procedencia del remedio, pues, siendo el cumplimiento posible, se cumple ya con sus condiciones. Pero a pesar de esta constatación

${ }^{53}$ DíEz-Picazo, L., Fundamentos del derecho civil patrimonial. II. Las relaciones obligatorias, $6^{\text {a }}$ ed., Thomson Reuters-Civitas, Cizur Menor-Navarra, 2008, p. 500.

${ }^{54}$ Ibidem.

55 Así, al menos, se ha fallado en diversas ocasiones por los tribunales españoles. Vid. SEvERIN Fuster, G., "El cumplimiento específico de los contratos de servicio en el derecho español", en Revista de Derecho Privado de la Universidad Externado de Colombia, No 30, 2016, pp. 179-186; VIDAl Olivares, Á., La protección del comprador. Régimen de la Convención de Viena y su contraste con el Código Civil, Ediciones Universitarias de Valparaíso, Valparaíso, 2006, pp. 177-179.

${ }^{56}$ López Díaz, P., "El abuso del derecho de opción del acreedor y su importancia en la construcción de un sistema equilibrado de remedios”, en Revista Chilena de Derecho Privado, No 19, Santiago, 2012, pp. $13-62$. 
no debiera acceder a una solicitud como esta, que merme principios contractuales superiores y que también se encuentran reconocidos normativamente ${ }^{57}$.

Para efectuar el análisis de ponderación que se exige al juez al momento que el deudor reclame que se le libere del cumplimiento específico y se sustituya el remedio por otro, ya sea la indemnización, la resolución del contrato o, incluso, la operación de reemplazo, deben tenerse en cuenta ciertos parámetros. La tarea implica considerar de manera objetiva el propósito práctico del contrato, desechando consideraciones subjetivas de las partes. No es posibe tener en cuenta las inquietudes propias a la época de celebración, sino que debe auscultarse mediante la interpretación del proceso de formación del contrato, el contenido del mismo, su ejecución y cuál era la finalidad económica, para dirimir ese primer aspecto de la ponderación.

Un segundo aspecto que se debe tener en cuenta es la imposibilidad de revisar, por medio de este límite, el equilibrio económico del contrato. No se trata de volver al momento de su perfeccionamiento y considerar si fue un buen o mal negocio para el deudor; lo que debe ser impermeable al análisis de la economía del contrato es el costo que significa la ejecución correcta de la prestación, como un parámetro en sí mismo.

No obstante, y por el mismo respeto al correcto comportamiento de las partes y del principio de buena fe contractual, debiera excluirse este límite si el deudor busca validar un incumplimiento eficiente, incurriendo en la denominada "culpa lucrativa", en términos que abstenerse del cumplimiento le signifique beneficios perseguidos con el remedio alternativo. El caso paradigmático en el incumplimiento de la promesa para la venta a un tercero que ofrece un mejor precio $^{58}$.

Por último, otro criterio que podría aportar a la decisión acerca de si procede o no el límite, es la situación de terceros. Por ejemplo, respecto de comerciantes que mantienen negocios en un inmueble cuya demolición es la ejecución forzada del contrato a la que se ha resistido el deudor. En este sentido la jurisprudencia francesa de la Corte de Casación sostuvo que "la ejecución en naturaleza se encuentra justificada en su principio pero que una demolición de construcciones tendría consecuencias desproporcionadas con los supuestos y la dimensión del juicio, dado que conduciría a la destrucción de una decena de boutiques mantenidas por comerciantes ajenos al proceso y significaría un perjuicio a otros arrendatarios de boutiques durante los trabajos de acondicionamiento" 59 .

Una vez hechas estas prevenciones, lo cierto es que criterios de razonabilidad, buena fe contractual y la proscripción del abuso del derecho, han creado el ambiente

57 WÈrY, Patrick, L'exécution forcée en nature des obligations contractuelles non pécuniaires. Une relecture des articles 1142 à 1144 du Code civil, Kluwer Éditions Juridiques Belgique, Bruxelles, 1993, p. 151; VINEY, Geneviève, "Exécution de l'obligation, faculté de remplacement et réparation en nature en droit français", in Fontaine, Marcel, Viney, Geneviève (dirs.), Les sanctions de l'inexécution des obligations contractuelles. Études de droit comparé, Bruylant-LGDJ, Bruxelles-Paris, 2001, pp. 183, 184.

${ }^{58}$ Laithier, Y. M., "Les sanctions de l'inexécutions du contrat", en Revue des contrats, abril, hors serie, 2016, p. 42.

${ }^{59}$ Corte de casación, Tercera Sala Civil, 3 de abril de 1996, Nº 94-14485, bulletin civil, III, No 91 , Laithier, Yves Marie, "Les sanctions de l'inexécutions du contrat", en Revue des contrats, abril, hors serie, 2016, nota 29, p. 42. 
para aceptar este límite al cumplimiento. Todas estas son herramientas provistas por el propio derecho continental; empero, un cierto sector de la doctrina ha pretendido acercarlo a aquellas limitaciones anglosajonas por medio de la restricción general a la indemnización del duty to mitigate o carga de minimizar el daño ${ }^{60}$.

Sobre la base de los elementos previstos en la Convención de Viena, esta postura plantea que la carga que pesa sobre el acreedor de mitigar sus propias pérdidas constituiría un "mecanismo de presión mediata" para que este no escogiera un cumplimiento insensato como remedio. Así como operan cargas de conducta y de comunicación para el acreedor, también debe incluirse una gestión razonable de los remedios contractuales. De no ser así y de requerirse el cumplimiento específico, en circunstancias en que este, por sus particulares características, puede provocar mayores daños, será la suma que se pida a título de indemnización la que se verá reducida ${ }^{61}$.

El problema de este planteamiento es que el derecho al cumplimiento permanece incólume si es que se llega a hacer efectivo por el acreedor. Más allá de una intimidación psicológica que pudiese afectarlo para evitar una eventual reducción en el monto de los daños, la carga de minimizar las pérdidas no constituye un genuino límite al cumplimiento en un ordenamiento continental, como sí lo son la buena fe contractual o su concreción en la teoría del abuso del derecho.

Pero ¿por qué esta interpretación podría aplicarse en el régimen de la Convención de Viena y no en uno continental? Muy probablemente, la respuesta es porque dicho instrumento constituye una norma de consenso, que manifiestamente intenta acercar las posiciones entre estos sistemas y aquellos de raíz anglosajona ${ }^{62}$. No obstante, para saber cuál sería su posible aplicación en Chile, nuevamente debe acudirse al que hemos llamado "ambiente contractual".

${ }^{60}$ Vidal Olivares, Á., "La gestión razonable de los efectos del incumplimiento en la compraventa internacional", en Revista de Derecho de la Universidad Austral de Chile, No 2, Vol. XVIII, 2005, disponible en http://www.scielo.cl/scielo.php?script=sci_arttext\&pid=S0718-09502005000200003, consultada el 24 de octubre de 2017; López Santa María, J., "Informe en derecho sobre la obligación del acreedor de una indemnización de mitigar o atenuar los daños. Contrato de transporte marítimo”, en Revista Chilena de Derecho Privado, No 8, 2007, pp. 203 y ss; López SAnta María, J., "Sobre la obligación de minimizar los daños en el derecho chileno comparado”, en Mantilla, F. y Ternera, F. (eds.), Los contratos en el Derecho Privado, Bogotá, 2007.

${ }^{61}$ Vidal Olivares, Á., "La gestión razonable de los efectos del incumplimiento en la compraventa internacional", en Revista de Derecho de la Universidad Austral de Chile, No 2, Vol. XVIII, 2005, pp. 55-81; Bahamondes Oyarzún, C., "Concurrencia de la indemnización de daños y la pretensión de cumplimiento específico frente al incumplimiento contractual”, en Cuadernos de Análisis Jurídico VII. Incumplimiento contractual. Nuevas perspectivas, Ediciones Universidad Diego Portales, Santiago, 2011, pp. 260, 261.

62 De hecho, la Convención de las Naciones Unidas sobre los contratos de compraventa internacional de mercaderías es un buen ejemplo de consenso entre los sistemas del common law -a excepción del Reino Unido que no la ha ratificado- y los continentales, por ejemplo, respecto del principio de buena fe. Su específica consagración, a propósito de la interpretación de dicho instrumento internacional (art. 7) contrasta con la amplitud con que el principio de razonabilidad es reconocido y aplicado en múltiples disposiciones. HofmanN, N., "Interpretation Rules and Good Faith as Obstacles to the UK's Ratification of the CISG and Harmonization of Contract Law in Europe", en Pace International Law Review, 2010, pp. 145-181, disponible en http://www.cisg.law.pace.edu/cisg/biblio/hofmann.html, fecha de consulta 8 de marzo de 2017. 
En el common law se parte, como ya sabemos, del principio inverso al continental, en que prima la indemnización, pero con excepcionales espacios para que se introduzca la specific performance mediante el adecuacy test ${ }^{63}$. Desde la perspectiva del common law y de su organización de remedios, es comprensible la necesidad de introducir el deber de minimizar el daño, ya que, lógicamente, el acreedor optará por -o se le forzará a recibiren la mayoría de los casos, una indemnización de perjuicios. Lo anterior determina por qué esta institución ha recibido tan escasa o nula atención en los sistemas continentales; se trata de una explicación cultural que va enlazada con la forma en que se construye el conjunto de remedios contractuales. El privilegio o la jerarquía que históricamente caracterizaron al cumplimiento in natura relegó a la minimización del daño a un páramo que no concitó mayor interés, por cuanto la medida se entiende mejor en un ambiente que privilegia la indemnización. En un caso de breach of contract no solo el deudor es consciente que deberá pagar una indemnización, sino que su acreedor también puede prever que la solución regular frente al incumplimiento será recibir dicha suma. En ese "ambiente contractual" es sensato que el acreedor oriente su conducta a reducir el daño, pues todo perjuicio que hubiere podido evitar con una mediana diligencia no le será indemnizado ${ }^{64}$.

Como se apuntó más arriba, pese a la existencia de breves espacios en que el cumplimiento específico tiene cabida y más allá del pago de una suma debida, la indemnización sigue siendo el remedio primordial aplicable en el common law para el incumplimiento contractual. Y en este contexto, ella siempre irá acompañada del deber de mitigar el daño. Esta regla de reciprocidad permite un equilibro en la aplicación de la sanción indemnizatoria con el deber de mitigar las pérdidas desde el momento del incumplimiento contractual.

Es más, la propia doctrina angloamericana ha reconocido que esta es una característica que plantea ventajas del cumplimiento específico por sobre los damages. Primeramente, el cumplimiento puede beneficiar a terceros, para quienes la demanda de indemnización contractual está vetada. Pero más importante aún, este remedio no está sujeto a reducción, como sí lo están las sumas indemnizatorias. Y en caso de que el remedio imponga, para una parte, costos que excedan el beneficio de la otra, lo que sucederá será que ese contrato debe finalizarse; se tolera su término hasta el punto en que ni siquiera habrá lugar para las restituciones de los beneficios obtenidos ${ }^{65}$.

${ }^{63}$ Beatson, J., Burrows, A., Catwright, J., Anson's Law of Contract, 29 ed., Oxford University Press, New York, 2010, p. 573; Treitel, G., Remedies for Breach of Contract: a comparative account, Clarendon Press Oxford, New York, 1989, p. 63; Bellivier, F. y Sefton-Green, R., "Force obligatoire et exécution en nature du contrat en droit français et anglais. Bonnes et mauvaises surprises du comparatisme”, en Études offertes à Jacques Ghestin. Le contrat au debut du XXI siècle, LGDJ, Paris, 2001, p. 95.

64 Sobre esto Vidal Olivares, Á., "La carga de mitigar las pérdidas del acreedor”, en GuZMáN Brito, A. (coordinador), en Estudios de Derecho Civil III, Santiago, 2008, p. 429 y ss.; Pizarro Wilson, C., "Contra el fatalismo del perjuicio. A propósito del deber de mitigar el daño", en Revista de Derecho, Pontificia Universidad Católica de Valparaíso, Vol. XLI, 2013, pp. 69 y ss.

${ }^{65}$ Friedmann, D., "Economic Aspects of Damages and Specific Performance Compared", in Saidov, D., Cunnington, R. (eds.), Contract Damages. Domestic and International Perspectives, Hart Publishing, Oxford, 2008, pp. 82-90. 
Entonces, es posible preguntar nuevamente si en Chile podría aplicarse la minimización de las pérdidas como un "mecanismo de presión mediata" que disuada de exigir un cumplimiento que tenga un coste excesivo para el deudor. Curiosamente, la flexibilización que el nuevo derecho de la contratación ha aportado al sistema de remedios, a nivel doctrinal y en forma incipiente en la jurisprudencia, ha independizado las acciones y el estudio de cada una de ellas ${ }^{66}$, encontrándose ausente hasta ahora la relación entre el deber de minimizar las pérdidas y los ajustes a los remedios contractuales.

Atrás quedaron las interpretaciones que obligaban al acreedor a pedir la indemnización solo si esta iba acompañada de una demanda de cumplimiento o de resolución. La autonomía de la acción indemnizatoria se encuentra bien instalada. Hoy es posible que los contratantes escojan la vía que les resulte más conveniente para satisfacer sus intereses, de manera complementaria o autónoma, mas no excluyente ${ }^{67}$.

Y la respuesta al interrogante planteado parece ir por la negativa. En los ordenamientos de raigambre continental, el cumplimiento es un genuino remedio que necesita límites propios, sin que deba recurrirse al deber de mitigar para justificar la improcedencia de la ejecución forzada. Una vez configurado, o se concede, o se rechaza. Y esta decisión, que corresponde al juez, operará con independencia de una eventual demanda de indemnización complementaria. Pensar en evitar una mengua en el importe indemnizatorio podría presionar al acreedor -en su fuero interno- al momento de decidir reclamar el cumplimiento, implica retroceder a una discusión mucho más antigua y nada novedosa: el reconocimiento mismo de esta carga. No se percibe aún, ni siquiera por vía de condicionar cumplimiento específico, que un elemento propio del sistema anglosajón pueda atenuar la relevancia del principio de reparación integral del daño. Cosa distinta es que este mismo principio y las reglas de la causalidad permitan excluir, de dichos perjuicios, aquellos que no fueron consecuencia directa y necesaria del incumplimiento, y que más bien provienen de la acción u omisión del propio acreedor ${ }^{68}$.

Podemos concluir, entonces, que resulta aceptable la recepción de este límite, imponiendo la necesidad de ponderar el cumplimiento y el beneficio que se obtendrá atendido el propósito práctico y las consecuencias económicas para el deudor. Siguiendo el ejemplo francés, el ideal sería que dicha recepción operase por medio de una reforma al derecho de los contratos que ya comienza a manifestar su urgencia. Con todo, en la latente espera resulta prudente recurrir a los estándares de la buena fe y el abuso del derecho, para que el juez pueda justificar el rechazo de las pretensiones del acreedor, si el cumplimiento específico arroja una desproporción entre su beneficio y un costo desmedido o irracional para el deudor.

${ }^{66}$ Como ha demostrado López DíAz, P., "La autonomía de daños en la jurisprudencia nacional recierte: ¿un cambio de paradigma?, en Revista Chilena de Derecho Privado, No 23, Santiago, pp. 139-207.

${ }^{67}$ Por todos, véase López DíAz, P., La autonomía de la indemnización de daños por incumplimiento de un contrato bilateral en el Código Civil chileno, Thomson Reuters-La Ley, Santiago, 2015, 369 pp.

${ }^{68}$ Sobre esto, Pizarro Wilson, C., "El hecho del acreedor", en Vidal Olivares, Álvaro, Severin Fuster, Gonzalo, Mejías Alonzo, Claudia (eds.), Estudios de derecho civil X, Thomson Reuters-La Ley, Santiago, 2015, pp. 624-630. 


\section{CONCLUSIONES}

Hemos podido observar que la posición que ocupa el cumplimiento específico no solo trasunta una mirada desde la fuerza obligatoria del contrato, sino que influye en la recepción o rechazo de otras instituciones pertenecientes al engranaje del incumplimiento, conforme se inserte en un determinado "ambiente contractual".

Con todo, las diferencias culturales y aproximaciones jurídicas expuestas no son óbice para constatar que pueden existir ciertos acercamientos que morigeran las posiciones. Esta atenuación de la dicotomía se verifica a propósito de los límites que puede enfrentar el cumplimiento específico en el derecho continental y, en lo que refiere al common law, en las excepciones o casos específicos en que procede la specific performance. Si consideramos que la fuerza obligatoria no impide plantear los remedios al incumplimiento contractual en posición de equilibrio y no de una jerarquía ab initio, debemos interrogarnos acerca de los límites que se debieran considerar para afirmar el decaimiento del cumplimiento específico como remedio principal.

La lejanía que aflora con el análisis del cumplimiento específico y la specific performance se atenúan en alguna medida si consideramos las excepciones que presenta o que se vienen decantando en los procesos de reforma en el derecho continental y en los estándares que permiten aceptar dicho remedio en el common law.

Es probable que las influencias recíprocas y sinergias entre los sistemas legales expuestos decanten en un modelo continental en que, si bien se reconoce un espacio al cumplimiento específico, este no rija en forma absoluta, dejando espacios para otras soluciones acordes con su ambiente contractual. Por su parte, el common law nos inspira también una mirada atemperada. La specific performance no está tan arrinconada como a prima facie puede creerse, debido a que los estándares que propone la jurisprudencia anglosajona son bastante amplios para permitirle un ámbito de aplicación creciente. Con esto, la supuesta reina de las sanciones por incumplimiento contractual en el derecho continental está cerca de tener su propia Bastille y en un espejo que refleja al common law podríamos vaticinar que la specific performance comienza a avanzar desde su sitial de plebeya.

\section{BIBLIOGRAFÍA}

Abeliuk Manasevich, René, Las obligaciones, tomo II, $5^{\text {a }}$ ed., Editorial Jurídica, Santiago, 2010. Adame-Martínez, M. A., Specific Performance as the Preferred Remedy in Comparative Law and CISG, Thomson Reuters-Aranzadi, Cizur Menor-Navarra, 2013.

Aedo Barrena, Cristian, "Cargas o deberes en la posición contractual del acreedor con especial referencia a su mora de recibir, en Colección de estudios de Derecho civil en homenaje a la profesora Inés Pardo de Carvallo, Ediciones Universitarias de Valparaíso, Valparaíso, 2008.

Alessandri, Arturo, Somarriva, Manuel, Vodanovic, Antonio, Tratado de las obligaciones, tomos II y III, Editorial Jurídica, Santiago, 2004.

ANCEL, Pascal, "Force obligatoire et contenu obligationnel du contrat", en RTD civ., Dalloz, Paris 1999. 
Bahamondes Oyarzún, Claudia, "Concurrencia de la indemnización de daños y la pretensión de cumplimiento específico frente al incumplimiento contractual", en Cuadernos de Análisis Jurídico VII. Incumplimiento contractual. Nuevas perspectivas, Ediciones Universidad Diego Portales, Santiago, 2011.

Barros Bourie, Enrique, "La diferencia entre estar obligado y ser responsable en el derecho de los contratos”, Corral Talciani, H., Rodríguez Pinto, M. S. (coords.), en Estudios de Derecho Civil II, LexisNexis, Santiago, 2007.

Barros Bourie, Enrique, "Finalidad y alcance de las acciones y los remedios contractuales", en Guzmán Brito, A. (ed. científico), Estudios de derecho civil III, LexisNexis, Santiago, 2008.

Beale, Hugh, Fauvarque-Cosson, Bénédicte, Rutgers, Jacobien, Tallon, Denis, Vogenauer, Stefan, Cases, Materials and Text on Contract Law, 2 ed., Hart Publishing, Oxford, 2010.

Beatson, Jack, Anson's Law of Contract, 28 ed., Oxford University Press, New York, 2002.

Beatson, Jack, Burrows, Andrew, Catwright, John, Anson's Law of Contract, 29 ed., Oxford University Press, New York, 2010.

Bellivier, Florence y Sefton-Green, Ruth, "Force obligatoire et exécution en nature du contrat en droit français et anglais. Bonnes et mauvaises surprises du comparatisme”, en Études offertes à Jacques Ghestin. Le contrat au début du XXI siècle, LGDJ, Paris, 2001.

Cartwright, John, Contract Law. An introduction to the English Law of Contract for the Civil Lawyer, Hart Publishing, Oxford, 2007.

Claro Solar, Luis, Explicaciones de derecho civil chileno y comparado, Vol. 5, Tomo X, Editorial Jurídica, Santiago, 1979.

ChÉnedé, François, "De l'autonomie de la volonté à la justice commutative. Du mythe à la réalité", en Annuaire de l'institut Michel Villey, No 4, Paris, 2012.

Delebecque, Ph. "L'articulation et l'aménagement des sanctions de l'inexécution du contrat", en Droit et Patrimoine, 2016.

DenIS, Philippe, "Book III performance and non-performance of obligations and corresponding rights in the DCFR", en Sagaert, Vicent, Storme, Matthias E. y Terryn, Evelyne (eds.), The Draft Common Frame of Reference: national and comparative perspectives, Intersentia Publishing Ltd, Cambridge, Antwerp, Portland, 2012.

Deshayes, O., Genicon, T., Laithier, Y. M., Réforme du droit des contrats, du régime général et de la preuve des obligations. Commentaire article par article, Paris, LexisNexis, 2016.

Díez-Picazo, Luis, Fundamentos del derecho civil patrimonial. II. Las relaciones obligatorias, $6^{a}$ ed., Thomson Reuters-Civitas, Cizur Menor-Navarra, 2008.

Diurni, Giovanni, “Pagamento (Diritto Intermedio)”, en Enciclopedia del Diritto, Giuffrè, Milán, 1981.

Eisenberg, Melvin A., "Actual and Virtual Specific Performance. The Theory of Efficient Breach and the Indifference Principle in Contract Law”, en California Law Review, Vol. 93, $\mathrm{N}^{\circ} 4$, California, 2005.

Farnsworth, Edward Allan, Contracts, $4^{\mathrm{a}}$ ed., Aspen Publishers, Nueva York, 2004.

Fauvarque-Cosson, B. "Regards comparatiste sur l'exécution forcée en nature", en Revue de Droit des Contrats, 2006-2.

Flour, J., Aubert, J.L, Les obligations. Le rapport d'obligation, Sirey, Paris, 1999, tome III.

Friedmann, Daniel, "Economic Aspects of Damages and Specific Performance Compared", in Saidov, D., Cunnington, R. (eds.), Contract Damages. Domestic and International Perspectives, Hart Publishing, Oxford, 2008.

Fueyo Laneri, Fernando, Cumplimiento e incumplimiento de las obligaciones, $3^{\mathrm{a}}$ ed., Editorial Jurídica, Santiago, 2004. 
Gandarillas Serani, Cristian, "Algunas consideraciones acerca del deber de mitigación o minimización del daño frente al incumplimiento contractual”, en Pizarro, C. (coord.), Estudios de Derecho Civil IV, LegalPublishing, Santiago, 2009.

Gatica Pacheco, Sergio, Aspectos de la indemnización de perjuicios por incumplimiento del contrato, Editorial Jurídica, Santiago, 1959.

Gounot, Emannuel, Le principe de l'autonomie de la volonté en droit privé; contribution à l'étude critique de l'individualisme, thèse, Dijon, 1912.

Grimaldi, Michel, "El derecho continental frente a la mundialización”, en Pizarro Wilson, C. (coord.), Derecho y economía, Fundación Fernando Fueyo Laneri, Santiago, 2012.

Hofmann, Nathalie, "Interpretation Rules and Good Faith as Obstacles to the UK's Ratification of the CISG and Harmonization of Contract Law in Europe", en Pace International Law Review, 2010.

Kelsen, Hans, Teoría pura del derecho, Tejeira, J. (Trad.), Editora Nacional, Ciudad de México, 1981.

Kronman, Anthony T., "Specific performance", en The University of Chicago Law Review, Vol. XLV, $\mathrm{N}^{\circ}$ 2, Chicago, 1978.

LaIthier, Yves Marie, Étude comparative des sanctions de l'inexécution du contrat, LGDJ, Paris, 2004.

Laithier, Y. M., "La prétendue primauté de l'exécution forcée en nature", en Revue de Droit des Contrats, 2006.

Laithier, Yves Marie, "Les sanctions de l'inexécutions du contrat", en Revue des contrats, abril, hors serie, 2016.

Larroumet, Christian, Droit civil. Les obligations, le contrat, Tome III, 5 éd., Economica, Paris, 2003.

López Díaz, Patricia, "El abuso del derecho de opción del acreedor y su importancia en la construcción de un sistema equilibrado de remedios", en Revista Chilena de Derecho Privado, $\mathrm{N}^{\circ}$ 19, Santiago, 2012.

López DíAz, Patricia, La autonomía de la indemnización de daños por incumplimiento de un contrato bilateral en el Código Civil chileno, Thomson Reuters-La Ley, Santiago, 2015.

López Santa María, Jorge, "Informe en derecho sobre la obligación del acreedor de una indemnización de mitigar o atenuar los daños. Contrato de transporte marítimo”, en Revista Chilena de Derecho Privado, No 8, 2007.

López Santa María, Jorge, "Sobre la obligación de minimizar los daños en el derecho chileno comparado" en Mantilla, Fabricio y Ternera, Francisco (eds.), Los contratos en el Derecho Privado, Bogotá, 2007.

López Santa María, Jorge, Los contratos, 5a ed., LegalPublishing, Santiago, 2010.

MackaAy, Ejan, "The civil law of contract", en De Geest, G. (edit.), Contract Law and Economics, VI, Edward Elgar Publishing, Cheltenham, 2011.

Mazeaud, D. Comentario de jurisprudencia, nota en Dalloz, 1997, Corte de casación, 30 de abril de 1997. Morales Moreno, Antonio Manuel, "El 'propósito práctico', y la idea de negocio jurídico en Federico de Castro y Bravo (Notas en torno a la significación de la utilidad de la cosa en los negocios del tráfico)", en Anuario de Derecho Civil, $\mathrm{N}^{\circ} 4$, Vol. XXXVI, Madrid, 1983.

Morales Moreno, Antonio Manuel, La modernización del derecho de obligaciones, Thomson-Civitas Aranzadi, Cizur Menor-Navarra, 2006.

Morales Moreno, Antonio Manuel, "La noción unitaria de incumplimiento en la Propuesta de Modernización del Código Civil”, en González Pacanowska, Isabel, García Pérez, Carmen Leonor (coords.), Estudios sobre incumplimiento y resolución, Thomson Reuters-Aranzadi, Cizur Menor-Navarra, 2015.

Peñailillo Arévalo, Daniel, Las obligaciones: teoría general y clasificaciones. La resolución por incumplimiento, Editorial Jurídica, Santiago, 2003. 
Pereira Fredes, Esteban, ¿Por qué obligan los contratos? Justificación normativa de la obligatoriedad del vinculo contractual, Thomson Reuters, Santiago, 2016.

Pizarro Wilson, Carlos (coord.), El derecho de los contratos en Latinoamérica (Bases para unos principios de Derecho de los contratos), Fundación Fernando Fueyo Laneri, Santiago, 2012.

Pizarro Wilson, Carlos, "Contra el fatalismo del perjuicio. A propósito del deber de mitigar el daño”, en Revista de Derecho, Pontificia Universidad Católica de Valparaíso, Vol. XLI, 2013.

Pizarro Wilson, Carlos, "Hacia un sistema de remedios al incumplimiento contractual”, en Guzmán Brito, A. (eds.), Estudios de Derecho Civil III, LegalPublishing, Santiago, 2008.

Pizarro Wilson, Carlos, "Notas críticas sobre el fundamento de la fuerza obligatoria del contrato. Fuentes e interpretación del artículo 1545 del Código Civil chileno", en Pizarro Wilson, Carlos, Vidal Olivares, Álvaro, Incumplimiento contractual, resolución e indemnización de daños, Editorial de la Universidad del Rosario, Bogotá, 2010.

PiZarro Wilson, Carlos, "Los remedios al incumplimiento contractual en los proyectos franceses de reforma del Derecho de contratos", en Revista de Derecho de la Pontificia Universidad Católica de Valparaíso, Vol. XXXVI, Nº 1, 2011.

Pizarro Wilson, Carlos, "Notas acerca de los límites a la pretensión de cumplimiento específico", en Revista de Derecho de la Universidad Católica del Norte, Vol. XXI, Nº 1, 2014.

Pizarro Wilson, C. "El hecho del acreedor", en Estudios de Derecho Civil, X, Santiago, ThompsonReuters, 2015.

Ramos Pazos, René, De las obligaciones, $3^{\mathrm{a}}$ ed., Editorial Jurídica, Santiago, 2008.

Ranouil, Veronique, L'autonomie de la volonté: naissance et évolution d'un concept, Presses Universitaires de France, Paris, 1980.

RIEG, Alfred, Le rôle de la volonté dans l'acte juridique en droit civil français et allemand, thèse, LGDJ, Paris, 1961.

Rouhette, Georges, Contribution à l'étude critique de la notion de contrat, thèse, dactyl., Paris, 1965.

Ruz LÁRTiga, Gonzalo, "El derecho a la ejecución in natura en el cumplimiento de las obligaciones en Chile", en Departamento de la Derecho Privado de la Facultad de Ciencias Jurídicas y Sociales de la Universidad de Concepción (ed.), Estudios de Derecho Civil V, LegalPublishing, Santiago, 2010.

San Martín Neira, Lilian, La carga del perjudicado de evitar o mitigar el daño. Estudio históricocomparado, Universidad Externado de Colombia, Bogotá, 2012.

SEverin Fuster, Gonzalo, "El cumplimiento específico de los contratos de servicio en el derecho español”, en Revista de Derecho Privado de la Universidad Externado de Colombia, No 30, 2016.

Severin Fuster, Gonzalo, "Sobre el carácter secundario y discrecional del remedio del cumplimiento específico en el common law. Perspectiva histórica y aproximación actual”, en Revista Chilena de Derecho, Vol. XLIII, No 1, Santiago, 2016.

Treitel, Guenter, Remedies for Breach of Contract: a comparative account, Clarendon Press Oxford, New York, 1989.

Treitel, Guenter, The law of contract, Sweet \& Maxwell, London, 1999.

Verdera Server, Rafael, El cumplimiento forzoso de las obligaciones, Publicaciones del Real Colegio de España, Bolonia, 1995.

VINEY, Geneviève, Exécution de l'obligation, faculté de remplacement et réparation en nature en droit français, in Fontaine, Marcel, Viney, Geneviève (dirs.), Les sanctions de l'inexécution des obligations contractuelles. Études de droit comparé, Bruylant-LGDJ, Bruxelles-Paris, 2001.

Vidal Olivares, Álvaro, "La gestión razonable de los efectos del incumplimiento en la compraventa internacional", en Revista de Derecho de la Universidad Austral de Chile, $\mathrm{N}^{\circ} 2$, Vol. XVIII, 2005, disponible en http://www.scielo.cl/scielo.php?script=sci_arttext\&pid =S0718-09502005000200003 consultada el 24 de octubre de 2016 . 
Vidal Olivares, Álvaro, "La pretensión de cumplimiento específico y su inserción en el sistema de remedios por incumplimiento en el Código Civil", en Corral Talciani, H., Rodríguez Pinto, M. S. (coords.), Estudios de Derecho Civil II: Código Civil y principios generales, nuevos problemas, nuevas soluciones, LexisNexis, Santiago, 2007.

Vidal Olivares, Álvaro, La protección del comprador. Régimen de la Convención de Viena y su contraste con el Código Civil, Ediciones Universitarias de Valparaíso, Valparaíso, 2006.

Vidal Olivares, Álvaro, "El incumplimiento de obligaciones con objeto fungible y los remedios del acreedor afectado: una relectura de las disposiciones del 'Código Civil' sobre incumplimiento”, en Guzmán Brito, A. (ed. científico), El Código Civil de Chile (1855-2005), LexisNexis, Santiago, 2007.

Vidal Olivares, Álvaro, "La carga de mitigar las pérdidas del acreedor", en Guzmán Brito, Alejandro (coord.), en Estudios de Derecho Civil III, Santiago, 2008.

Vidal Olivares, Álvaro, "El incumplimiento y los remedios del acreedor en la Propuesta de modernización del derecho de las obligaciones español", en Revista Chilena de Derecho Privado, $\mathrm{N}^{\circ} 16,2011$.

Vidal Olivares, Álvaro, "La pretensión de cumplimiento específico de las obligaciones no dinerarias y los costes excesivos para el deudor como límite a su ejercicio", en Vidal Olivares, Álvaro, Severin Fuster, Gonzalo, Mejías Alonzo, Claudia (eds.), Estudios de derecho civil X, Thomson Reuters-La Ley, Santiago, 2015.

WÈry, Patrick, L'exécution forcée en nature des obligations contractuelles non pécuniaires. Une relecture des articles 1142 à 1144 du Code civil, Kluwer Éditions Juridiques Belgique, Bruxelles, 1993 , p. 151.

Zimmermann, Reinhard, Derecho romano, derecho contemporáneo, derecho europeo. La tradición del derecho civil en la actualidad, Rodríguez, J. (trad.) Universidad Externado, Bogotá, 2010.

Zweigert, Konrad, KöTz, Hein, Introduction to Comparative Law, 3 ed., Clarendon Press, Oxford, 1998. 
